\title{
Nano-decolorization of methylene blue by Phyllanthus reticulatus iron nanoparticles: an eco-friendly synthesis and its antimicrobial, phytotoxicity study
}

\author{
Rajathirajan Siva Dharshini ${ }^{1,2} \cdot$ Mani Poonkothai $^{1} \cdot$ Palanisamy Srinivasan $^{3} \cdot$ Raja Mythili $^{3} \cdot$ Asad Syed $^{4}$. \\ Abdallah M. Elgorban ${ }^{4}$. Thangasamy Selvankumar ${ }^{3}$. Woong Kim ${ }^{5}$
}

Received: 14 May 2021 / Accepted: 19 July 2021 / Published online: 31 July 2021

(c) King Abdulaziz City for Science and Technology 2021

\begin{abstract}
The present study was investigated to synthesis the iron nanoparticles (FeNPs) using the leaf extract of Phyllanthus reticulatus. The phytosynthesized FeNPs exhibited UV-visible absorption peaks at $229 \mathrm{~nm}$ and its crystalline nature was confirmed through XRD. FT-IR analysis revealed the presence of various functional groups which are responsible for the bioreduction of FeNPs. The SEM results showed that FeNPs were aggregated, irregular sphere shaped with rough surfaces and EDX spectrum recorded densely occupied iron nanoparticles region. The particle size range of the synthesized iron nanoparticles was $185.6 \mathrm{~nm}$. The FeNPs showed potential methylene blue decolourisation activity which was visually observed by gradual colour change in the dye solution from deep blue to colorless. The control exhibited no change in coloration during exposure to sunlight and the iron nanoparticles completely disintegrated the methylene blue within $10 \mathrm{~s}$ in $10 \mathrm{mg} / \mathrm{L}$ methylene blue (98\%), whereas the color change was decreased when the concentration of the dye increased. In addition, the phytosynthesized FeNPs exhibited extensive antibacterial and antifungal activity against the selected pathogens. Phytotoxicity assay confirms the potential of biosynthesized iron nanoparticles as a fertilizer for the growth of green gram seeds. Thus the present study leads to development of cost-effective green synthesis, reduction of toxic chemicals and its extensive applications in the biological sciences.
\end{abstract}

Keywords Phyllanthus reticulatus $\cdot$ Iron nanoparticles $\cdot$ Photocatalytic activity $\cdot$ Phytotoxic activity $\cdot$ Antimicrobial activity

Mani Poonkothai

poonkothaii_zoo@avinuty.ac.in

Woong Kim

elshine@knu.ac.kr

1 Department of Zoology, Avinashilingam Institute for Home Science and Higher Education for Women, Tamil Nadu, Coimbatore, India

2 Department of Genetic Engineering, Molecular Genetics Laboratory, School of Bioengineering, SRM Institute of Engineering and Technology, Kattankulathur, Kanchipuram, Chennai, Tamilnadu 603203, India

3 PG \& Research Department of Biotechnology, Mahendra Arts and Science College (Autonomous), Tamil Nadu, Kalippatti, Namakkal 637501, India

4 Department of Botany and Microbiology, College of Science, King Saud University, 2455, Riyadh 11451, Saudi Arabia

5 Department of Environmental Engineering, Kyungpook National University, Daegu, South Korea

\section{Introduction}

Synthesis, manipulation and use of nanoscale size materials and/or nanoparticles have attracted much attention due to their unique properties and applications in the field of science and technology and medicine (Praveen et al. 2018). Among, the synthesis methods, green and/or biosynthesis of metal nanoparticles gained increasing attention due to their eco-friendly, cost-effective, reproducible nature and large-scale synthesis (Sengottaiyan et al. 2016; Selvam et al. 2017; Arularasu et al. 2018; Mythili et al. 2018). Among the metal nanoparticles, iron nanoparticles (FeNPs) have been widely applied as in solar energy conversion, biomedical applications, drug delivery and also as a catalyst (Kumar and Gupta 2005). In addition, FeNPs possess strong toxicity against a broad spectrum of pathogenic bacteria and fungi (Mahmoud et al. 2011). Because of excellent properties and applications, FeNPs synthesis using bio-based materials has attracted much attention in the field of nanoscience and 
technology. Nanoparticles synthesized using plant extract resulted in the photocatalytic degradation of organic dyes which was found to be time dependent and moreover, there was no loss of activity of the nanoparticles until the reuse of particles (Goswami et al. 2018).

Biosynthesis of FeNPs has been reported using microorganisms, enzymes and plants (Devatha et al. 2016; Raj et al. 2018). Among the biological sources, plant-based materials are advantageous because, they contain higher bioactive molecules and/or secondary metabolites which can be effectively reduced and act as a capping agent for the synthesis of FeNPs (Charbgoo et al. 2017). Studies on the synthesis of FeNPs using plants have been documented by several researchers (Mohan Kumar et al. 2013; Huang et al. 2014; Wang et al. 2014), however, to date, synthesis of FeNPs using Phyllanthus reticulatus has not been reported.

Phyllanthus reticulatus (Poir.) (Black honey shrub) belongs to the family Euphorbiaceae is widespread in India and tropical Africa. It act as an diuretic, antidiabetic and antidiarrheal agent and reported to contain various phytochemicals such as lupeol, lupeol acetate, and stigmasterol, polyphenols, flavonoids, glycosides, tannic acid and octacosanol (Khatun et al. 2014). Since, the plant contains variety of secondary metabolites and/or bioactive molecules it could be used as biological reducing agents for FeNPs synthesis. Hence the present study is an attempt to synthesis and characterize the FeNPs using P. reticulatus leaf extract and to assess the photocatalytic degradation of the methylene blue, antimicrobial activity and phytotoxicity of the synthesized nanoparticle under in vitro conditions.

\section{Materials and methods}

\section{Plant material and its extract preparation}

In this present study, the fresh leaves of $P$. reticulatus were collected from Mohanur, Namakkal district, Tamil Nadu, India and were identified by Botanical Survey of India (BSI/SRC/23/2018/Tech./2873), Tamil Nadu Agricultural University, Coimbatore, Tamil Nadu, India. To remove the dust particles present on the surface of the collected leaves, they were washed with running tap water followed by deionized distilled water. The surface cleaned leaves were shade dried for a week and crushed into fine powder with the help of a suitable grinder. The powder was stored in an airtight container and kept in a cool, dark and dry place for further analysis. About $10 \mathrm{~g}$ of powdered leaves were dissolved with $100 \mathrm{ml}$ of distilled water and boiled at $180-90{ }^{\circ} \mathrm{C}$ for $30 \mathrm{~min}$. The contents were filtered through Whatman No.1 filter paper and the obtained clear filtrate was stored at $4{ }^{\circ} \mathrm{C}$ for further FeNPs synthesis.

\section{Biobased green synthesis of iron nanoparticles}

Ferrous sulphate was prepared in different concentrations (1-5 mM) and to each 1-5 ml of the leaf extract was added separately. The reaction time was varied from 0 to $10 \mathrm{~min}$ and the contents were incubated at room temperature. At the optimized conditions, the reduction of $\mathrm{Fe}^{+}$to $\mathrm{Fe}^{0}$ was confirmed by the colour change of solution from yellow to black. The biosynthesized iron nanoparticles were centrifuged at $1000 \mathrm{rpm}$ for $5 \mathrm{~min}$ to obtain the black precipitate which served as iron nanoparticles. The obtained iron nanoparticles were dissolved in $100 \mathrm{ml}$ of double distilled water and stored at $4{ }^{\circ} \mathrm{C}$ for further analysis (Suruthika et al. 2020).

\section{Characterization of FeNPs}

The Phyllanthus reticulatus-mediated FeNPs was characterized by various spectroscopic techniques. The formation of FeNPs and the development of Surface Plasmon Resonance (SPR) peak were measured by UV-visible spectroscopy (Hitachi U2800, Tokyo, Japan). The morphology, size distribution and the elemental $\mathrm{Fe}$ of the prepared FeNPs were determined by scanning electron microscope equipped with X-ray energy dispersive spectrometer was employed (Nova, Bergenfield, USA). The FTIR (Shimadzu8400S, Kyoto, Japan) analysis was carried out to determine the possible secondary metabolites and/ or biomolecules which are involved the reduction and capping of FeNPs. X-ray diffraction (Shimadzu XRD 7000, Japan) was performed to determine the crystalline structure of FeNPs and the particle size range of the synthesized iron nanoparticles was determined using a particle size analyzer.

\section{Photocatalytic degradation activity}

Photocatalytic degradation activity of FeNPs was evaluated by the disintegration of methylene blue (MB) under sunlight irradiation. $500 \mathrm{mg}$ of FeNPs were dispersed in $100 \mathrm{ml}$ of distilled water. A series of screw cap tubes containing different concentrations of MB (10-50 mg/L) was taken and $1 \mathrm{ml}$ of prepared FeNPs solution was added separately to the dye solutions. The experimental setup was kept over the sunlight irradiation $14 \mathrm{~h}$ to observe the color change of the dye. The resultant solution was monitored in the wavelength range of $680 \mathrm{~nm}$ in a colorimeter and the percentage dye removal was calculated by

Dye removal $(\%)=\left(\mathrm{C}_{0}-\mathrm{C}\right) / \mathrm{C}_{0} \times 100$ 
Where $\mathrm{C}_{0}$ is the initial concentration of dye and $\mathrm{C}$ is the final concentration of dye at time (Bishnoi et al. 2018).

\section{Antimicrobial activity of synthesized iron nanoparticles}

The antibacterial and antifungal activity of the synthesized FeNPs was assessed by standard agar well diffusion method (Bauer et al. 1966). The bacterial cultures, Klebsiella pneumonia (MTCC 432), Shigella flexneri (MTCC 1457), Proteus vulgaris (MTCC 426), Salmonella typhi (MTCC 531), Vibrio cholera (MTCC 3906), Pseudomonas aeroginosa (MTCC 424), Staphylococcus aureus (MTCC 96) and Staphylococcus epidermidis (MTCC 435), and fungal cultures Aspergillus niger (MTCC 282), Aspergillus fumigatus (MTCC 9657), Aspergillus flavus (MTCC 277) and Trichoderma sp. (Accession number:KX856353) were used in the present study. The selected bacterial and fungal cultures were swabbed on the Muller Hinton agar (Bacteria) and Rose Bengal Chloramphenicol agar (Fungi) plates separately. To each well $20 \mu \mathrm{l}(100 \mu \mathrm{g})$ of the biosynthesized FeNPs, aqueous extract of $P$. reticulatus leaves and the standard antibiotics chloramphenicol (bacteria) and fluconazole (fungi) which served as positive control were added separately. The plates were then incubated at $37^{\circ} \mathrm{C}$ for $24 \mathrm{~h}$ (bacteria) and at room temperature for 5 days (fungi). To determine the antimicrobial activity, the diameter of inhibition zone was measured and expressed in millimeter.

\section{Phytotoxicity assay}

The green gram seeds subjected for germination assay were immersed in $10 \%$ sodium hypochlorite solution for $10 \mathrm{~min}$ to ensure surface sterility (USEPA 1996). After surface sterilization, the seeds were soaked in distilled water $\left(\mathrm{T}_{1}\right)$, plant extract $\left(\mathrm{T}_{2}\right)$ and iron nanoparticles $\left(\mathrm{T}_{3}\right)$ suspensions for about $24 \mathrm{~h}$ and rinsed thrice with distilled water. The experiment was conducted in triplicates. A layer of cotton was placed on each Petri dish and $5 \mathrm{ml}$ of the selected test medium was added separately. Seeds were then transferred onto the cotton layer, with ten seeds per dish and $1 \mathrm{~cm}$ distance between each seed. The plates were watered regularly with the selected treatment. Petri dishes were covered and placed in the dark chamber for 3 days. After 7 days of incubation, germination percentage, shoot length, root length and vigour index of the green gram seedlings were recorded (Anupama et al. 2014).

\section{Results and discussion}

Among the different concentrations of ferrous sulphate solution and plant extract used with the varying time intervals, the colour change from yellow to black was well observed immediately with $2 \mathrm{mM}$ ferrous sulphate with $1 \mathrm{ml}$ of leaf extract indicating the synthesis of iron nanoparticles (Fig. 1a). The change in the colour of the solution represented the reduction of ferrous sulphate to ferrous ions and thereby leads to the formation of FeNPs. The reaction mechanism might be due to the formation of a complex when the plant extract was added to the metal which breaks the $-\mathrm{OH}$ bond and forms a partial bond with the metal ion. Further there might be breakage of the partial bond and the transfer of electrons to reduce the metal ions to nanoparticles (Gottimukkala et al. 2017). Hence it is assured that biomolecules present in the leaf extract may function as reducing agent and capping agent.

UV-Vis spectral analysis (200-800 nm) of the biosynthesized FeNPs showed broad absorption peak around $229 \mathrm{~nm}$ (Fig. 1b). Devatha et al. (2016) observed the strong absorption peak of FeNPs at $259 \mathrm{~nm}$ and our results showed that strong absorption band at $229 \mathrm{~nm}$. The SEM image obtained for FeNPs synthesized from $P$. reticulatus and its corresponding EDX spectrum is shown in Fig. 2. SEM images revealed that the synthesized FeNPs were aggregated and irregular sphere shape with rough surfaces. Ali et al. (2016) reported spherical-shaped irregular iron oxide particles, which might have occurred due to agglomeration and its adhesiveness, the characteristic nature of metallic nanoparticles. To further validate the FeNPs, the elemental composition was determined by EDX. The EDX spectrum showed intense peak of $10.12 \%$ for $\mathrm{Cl}$, and $38.32 \%$ for O illustrating the existence of macromolecule as stabilizing agent on the surface of iron nanoparticles and also showed a strong signal of pure Fe with a weight percentage of $51.56 \%$. The presence of $\mathrm{Fe}$ and $\mathrm{O}$ peaks indicated the formation of FeNPs.

FT-IR analysis is carried out to determine the possible secondary metabolites and/or biomolecules responsible for the reduction of Fe ions (Fig. 3a). The strong absorption band at 3367.71 and $3255.84 \mathrm{~cm}^{-1}$ indicated the $\mathrm{OH}$ stretching vibrations and the presence of alcohols and phenols (Litvin et al. 2012). The peaks at 2985.8 and $2353.16 \mathrm{~cm}^{-1}$ indicates the $\mathrm{C}-\mathrm{H}$ stretching vibrations of alkanes and $-\mathrm{OH}$ stretching of amino acids. The peaks at 1639.49 and $1473.62 \mathrm{~cm}^{-1}$ may be assigned to the amide bond of the proteins and $\mathrm{C}=\mathrm{C}$ stretching of aromatic compounds. The absorption peak in the range of $1380-1240 \mathrm{~cm}^{-1}$ indicates $\mathrm{C}-\mathrm{N}$ stretch of aliphatic amines. It has been reported by Lin et al. (2005) that the carbonyl groups from the amino acid residues and peptides of proteins have a strong affinity to bind metals. So that protein can act as encapsulating agent and thus protect the nanoparticles from agglomeration. The amide linkages in proteins and polypeptides give wellknown signature in IR region. Presence of organic groups in the FT-IR spectrum of iron oxide nanoparticles indicated that bioactive compounds from $P$. reticulatus act as capping agent and decorate the surface of prepared particles. This

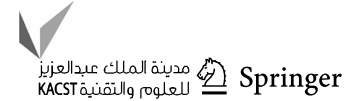


Fig. 1 a Formation of FeNPs from $P$. reticulatus leaf extract $\mathbf{b}$ UV-Vis spectrum of synthesized FeNPs (a) Formation of FeNPs from $P$. reticulatus leaf extract
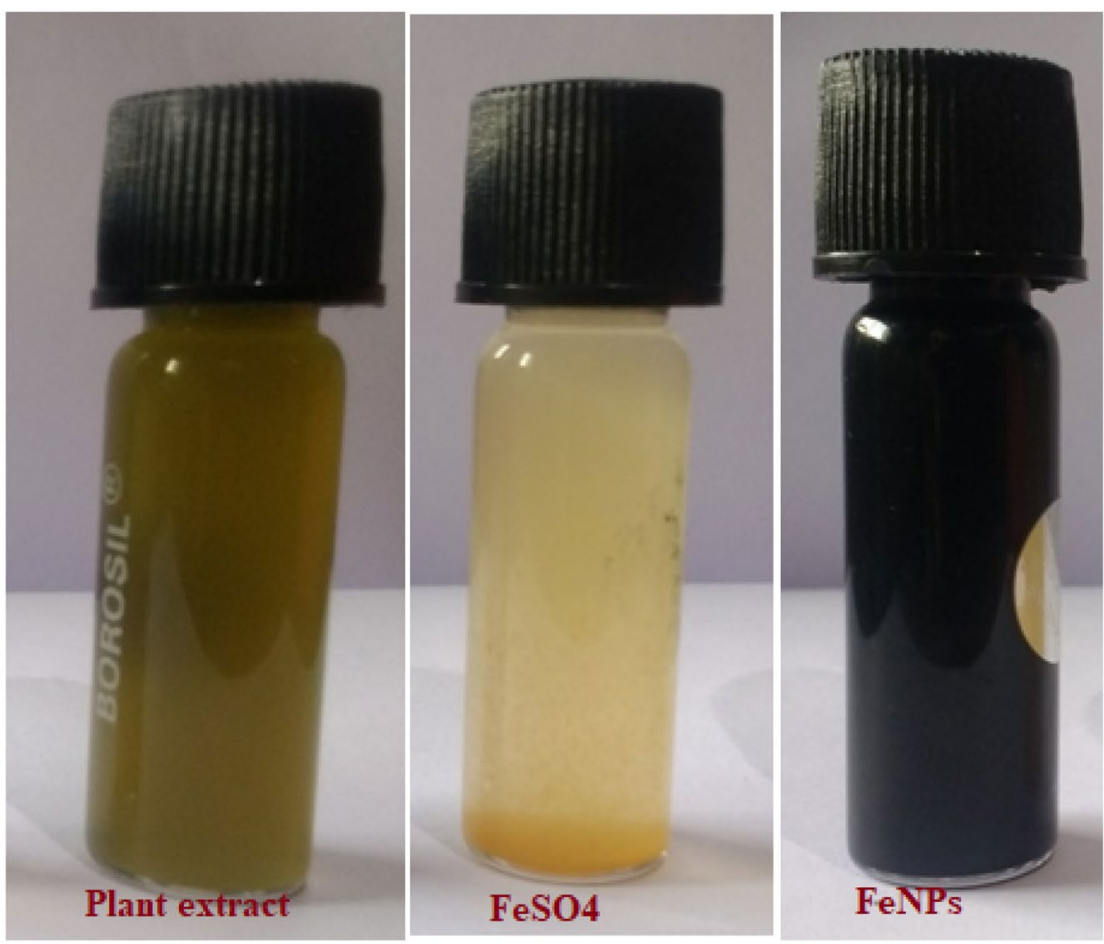

(b)UV-Vis spectrum of synthesized FeNPs.

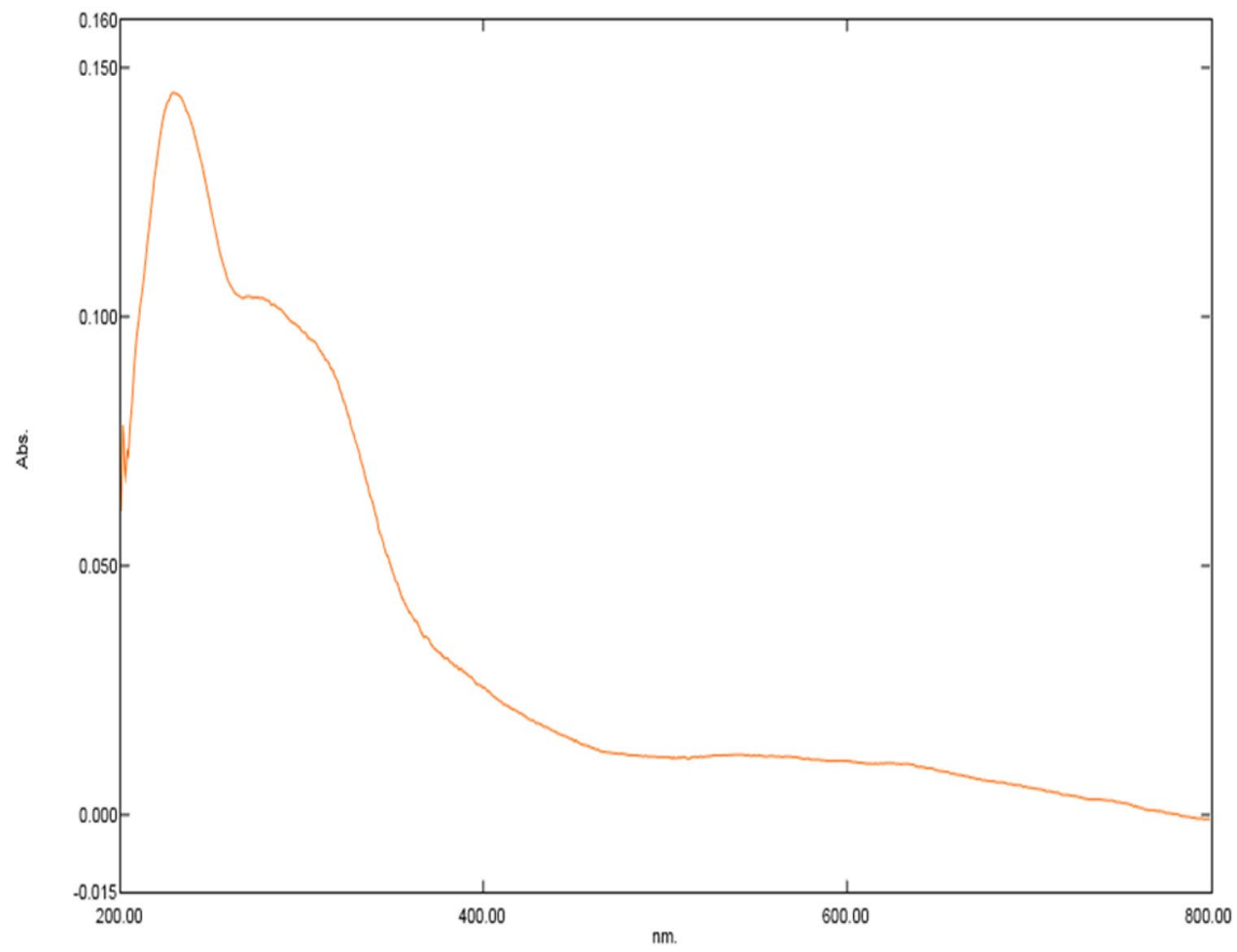




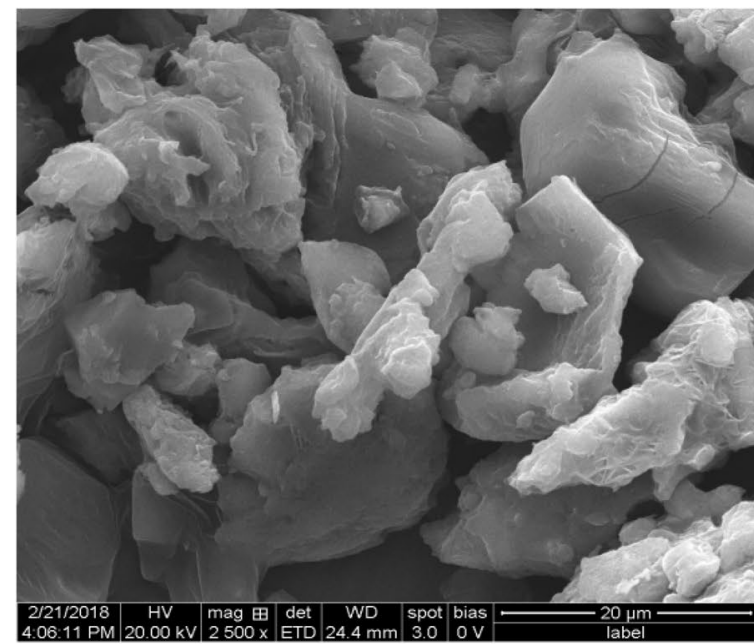

Fig. 2 SEM and EDX analysis of phytosynthesized FeNPs

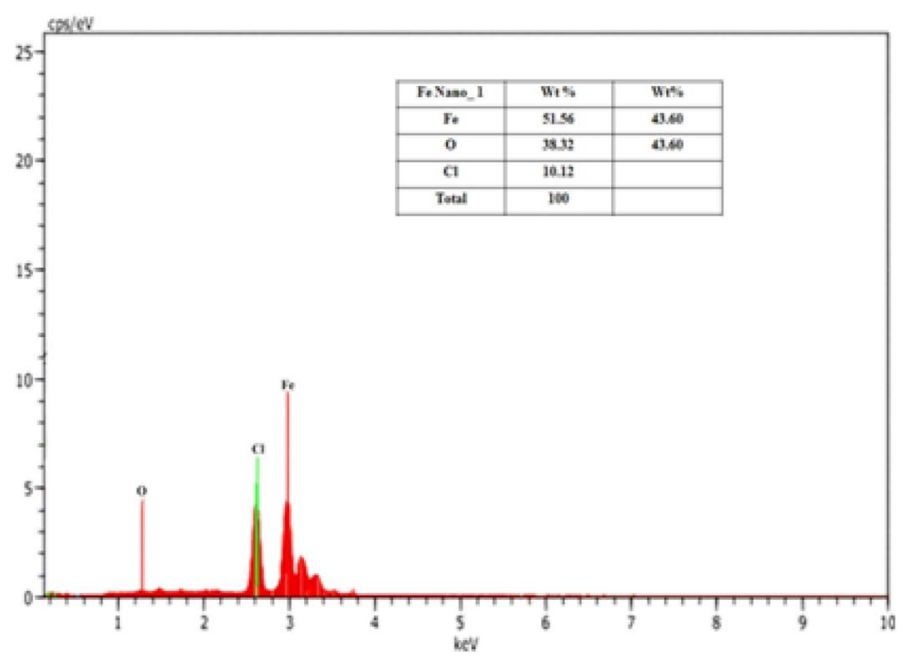

organic coating increases the chemical and colloidal stability of iron oxide nanoparticles and also can increase the biocompatibility of nanoparticles (Ebrahiminezhad et al. 2017). From the analysis of FT-IR study, it was revealed that the carbonyl group from the amino acid residue, carbohydrates and phytochemical constituents has the stronger ability to bind metal nanoparticles (capping of iron oxide nanoparticles) to prevent the agglomeration and thereby stabilize the medium. This suggests that biological molecules could possibly perform the dual function of formation and stabilization of iron oxide nanoparticles in the aqueous medium (Ali et al. 2016). Shah et al. (2015) also stated that presence of hydroxyl, carboxyl and amino functional groups may act as a precursor in metal ion reduction and also as capping agent to form the robust coating on the metal nanoparticles and leads to the colour change from yellowish brown to black.

The crystalline nature and phase composition of FeNPs were identified by X-ray diffractometer with Bragg's angle ranging from 20 to $80^{\circ}$ within $2 \theta$ range (Fig. $3 b$ ). The XRD pattern of biosynthesized iron nanoparticles exhibit several broad Bragg's peaks corresponding to 220, 400, 422 and 440 orientations respectively indicating its crystalline nature of FeNPs.

Dynamic light scattering is a widely used technique for the determination of particle size in colloidal solution. Particle size and distribution are the major characteristics to be determined for a nanoparticles based on its saturation solubility, dissolution velocity, physical stability or even biological performance (Vishal and Agarwal 2011). The resulting particle size of iron nanoparticles exhibits the size distribution of $185.6 \mathrm{~nm}$ (Fig. 4). These results are consistent with the UV-Vis spectra where broadness of absorption peak is proportional with the size of the particle. Prabhakar et al. (2017) reported that Mimosa pudica-based iron nanoparticles showed comparatively larger size distribution of 65-230 nm.

Photocatalytic degradation of methylene blue was investigated using green-synthesized FeNPs under solar light irradiation. The degradation was visually observed by gradual change in the colour of the dye solution from deep blue to colorless (Fig. 5). The control exhibited no change in coloration during exposure to sunlight and the iron nanoparticles completely disintegrated the methylene blue within $10 \mathrm{~s}$ in $10 \mathrm{mg} / \mathrm{L}$ dye (98\%), whereas the colour change was decreased in $20 \mathrm{mg} / \mathrm{L}(87 \%)$ and $30 \mathrm{mg} / \mathrm{L} \mathrm{(66 \% )} \mathrm{at} 25$ and $30 \mathrm{~min}$ of incubation, respectively. Minimum decolourisation was observed in $40 \mathrm{mg} / \mathrm{L}(27 \%)$ and $50 \mathrm{mg} / \mathrm{L}(15 \%)$ dye inoculated with $1 \mathrm{ml}$ of iron nanoparticles. It has been reported that the dye degradation is associated with the breakdown of chromophoric group of the methylene blue and the transformation of dye into the low molecular weight by-products. The results are consistent with previous studies reported the degradation of methyl orange and methylene blue using FeNPs synthesized from Amaranthus spinosus (Garole et al. 2018).The mechanism of degradation of dye took place due to the generation of surface plasmons under resonant excitation with molecular environment (Tsibul'nikova et al. 2015). It was also described by Maji et al. (2007) that the mechanism of degradation of dye might be due to photo-absorption, electrons and holes generation, charge carriers transfer and the recombination of carrier with the dye molecules. The high surface area of iron oxide nanoparticles in the present study assists the methylene blue degradation and increase the formation of hydroxyl radicals. The results of the present study coincides with the findings of Shahwan et al. (2011) who reported $80 \%$ removal of methylene blue dye within 5 min of sunlight irradiation and the remaining concentration of dye was decolourised after

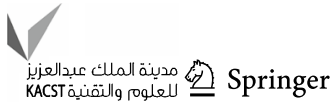


(a) FT-IR analysis of FeNPs.

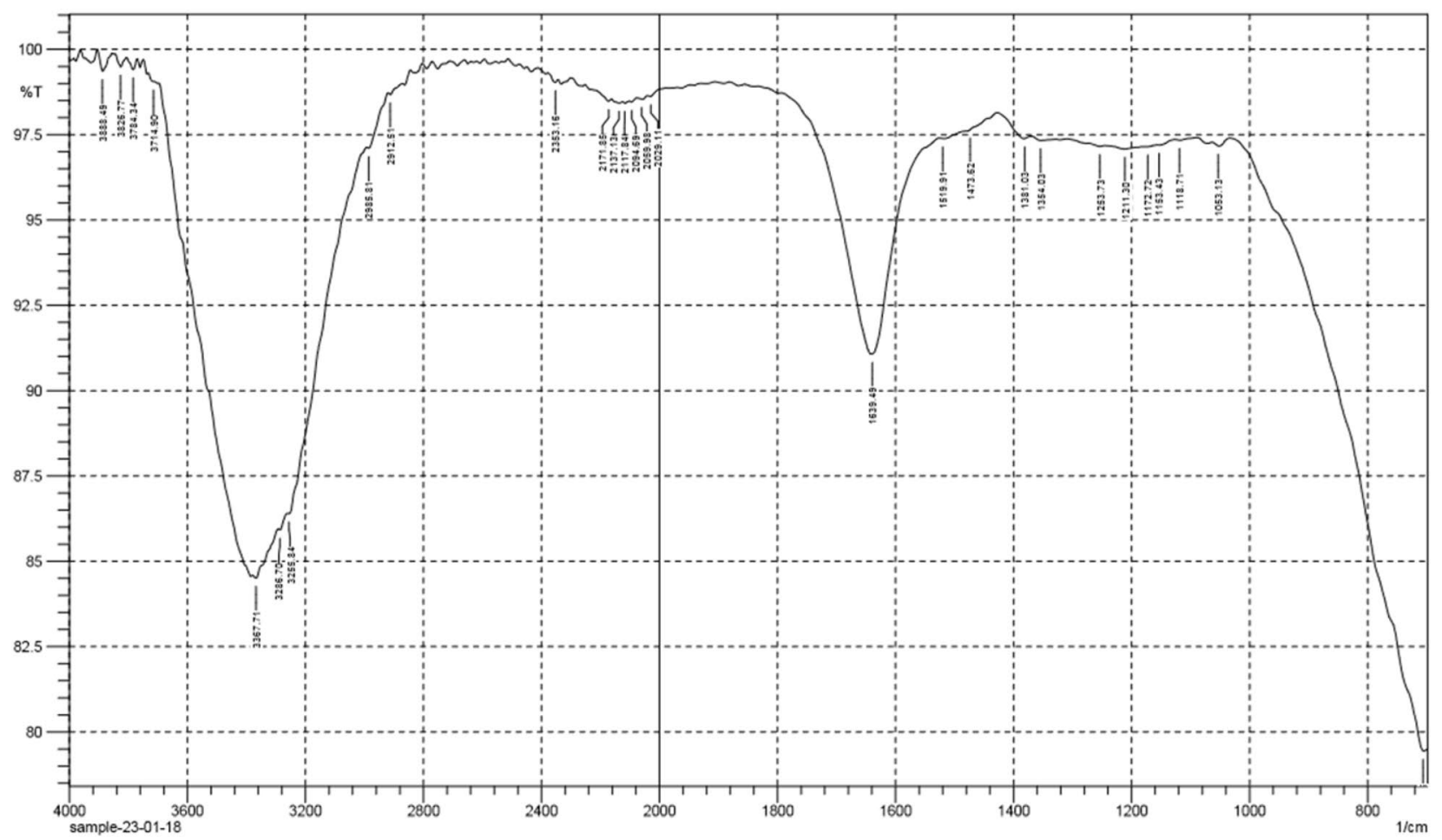

(b) XRD analysis of FeNPs

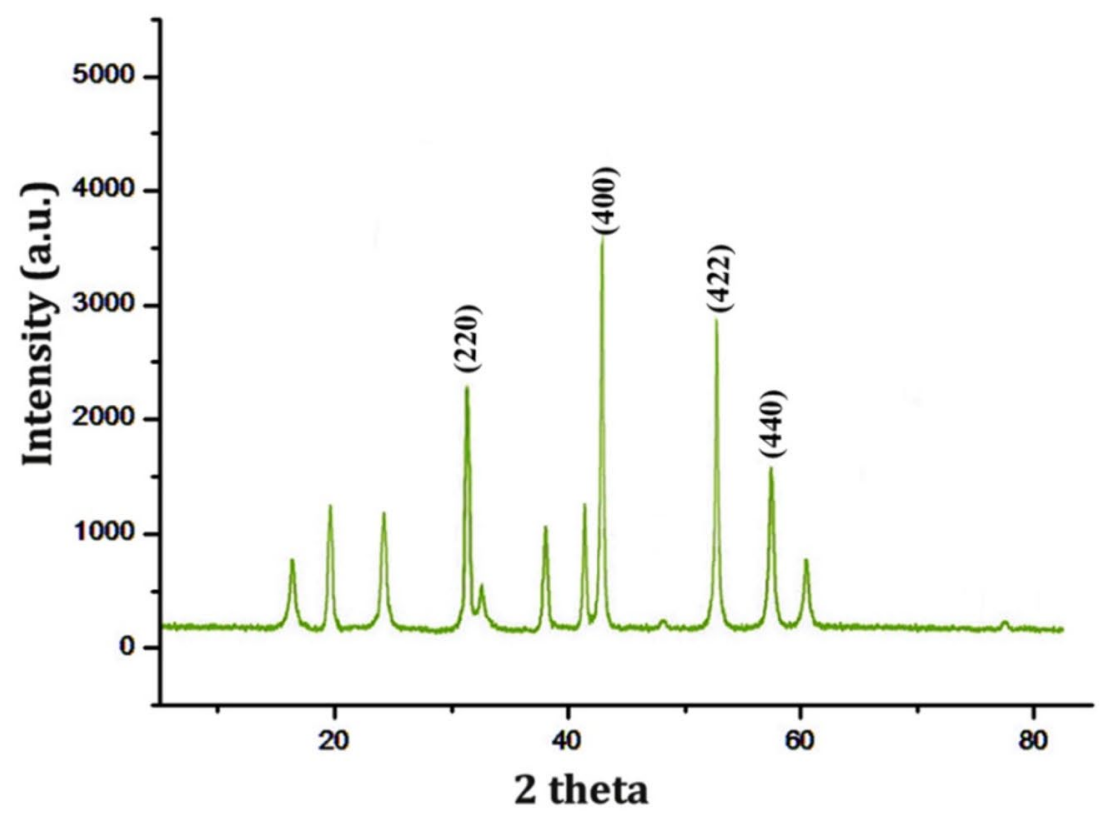

Fig. 3 a FT-IR analysis of FeNPs $\mathbf{b}$ XRD analysis of FeNPs 
Fig. 4 Particle size of biosynthesized iron oxide nanoparticles

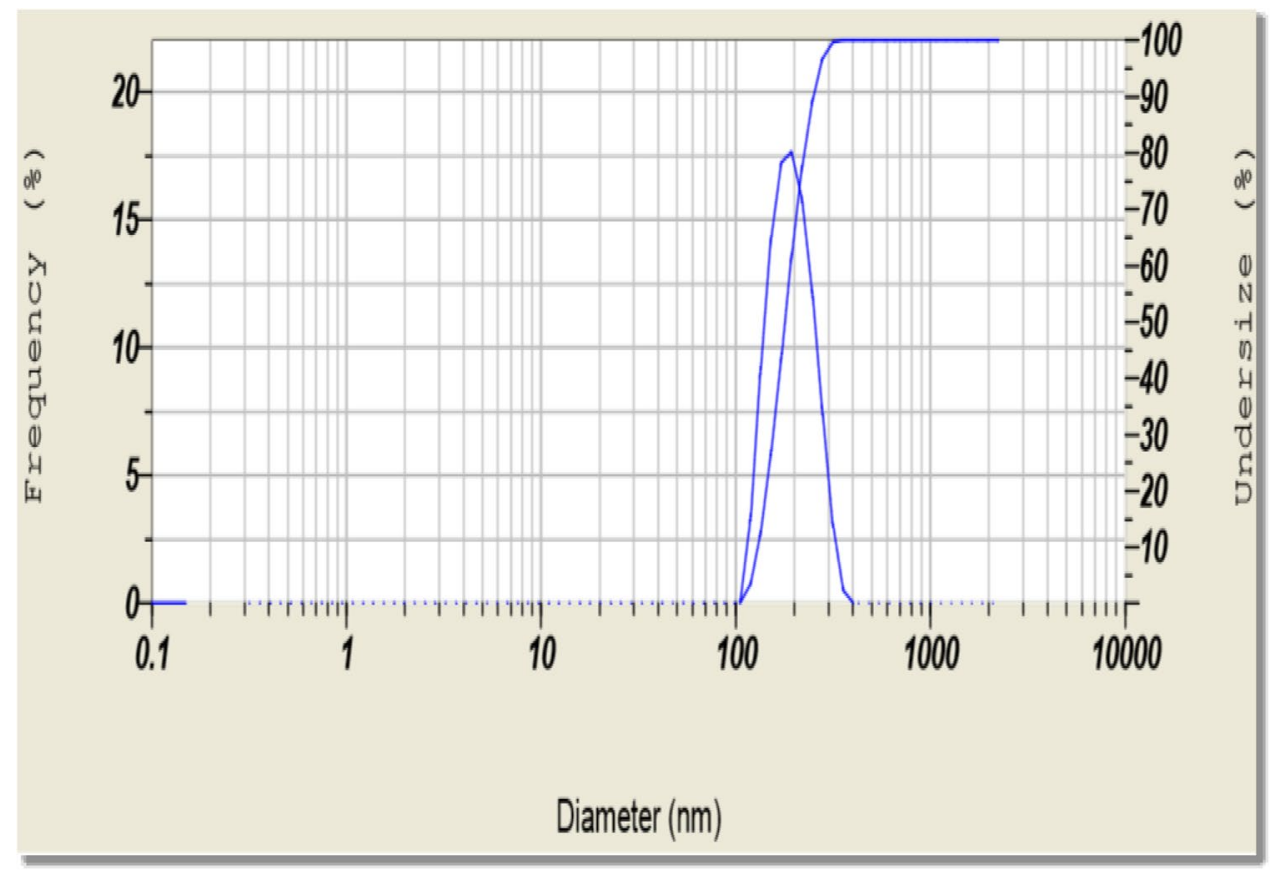

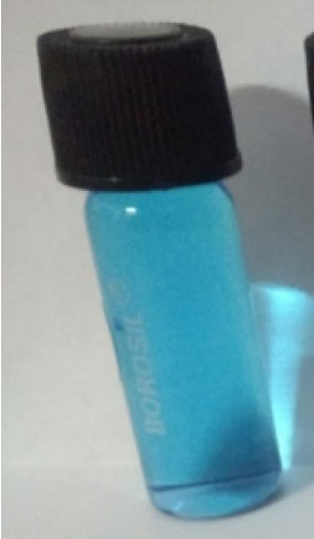

(a)

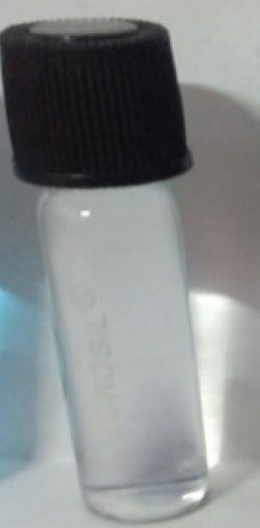

(b)

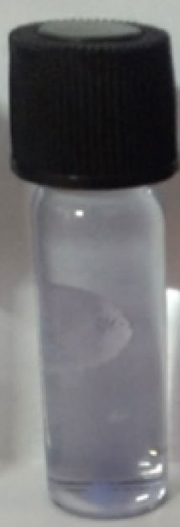

(c)

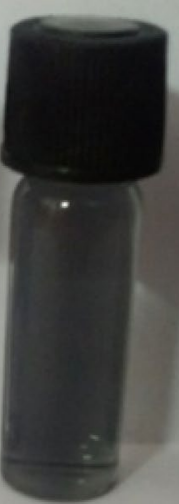

(d)

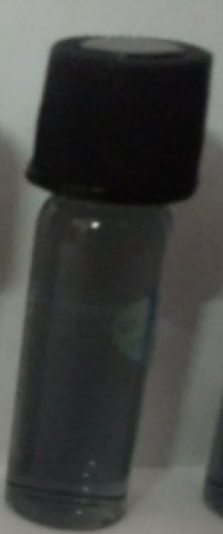

(e)

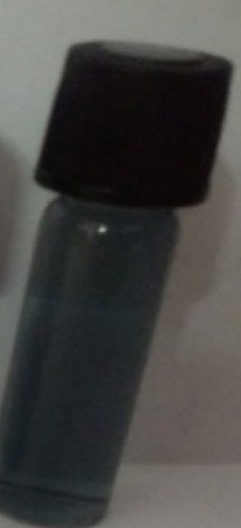

(f)

Fig. 5 Methylene blue degrading activity of FeNPs. A-Control (Methylene blue); B 10 mg/L FeNPs; C 20 mg/L FeNPs; D 30 mg/L FeNPs; E $40 \mathrm{mg} / \mathrm{L}$ FeNPs; and $\mathbf{F} 50 \mathrm{mg} / \mathrm{L}$ FeNPs

200 min under optimized conditions. Similar studies were performed using iron nanoparticles to remove malachite green by green tea leaf extract (Weng et al. 2013), indigo carmine by Azadirachta indica and methyl orange by benzoate supported nanoscale zerovalent iron (Chen et al. 2011). Govarthanan et al. (2021) investigated the photocatalytic degradation of methylene blue and rhodamine-B using the novel heterogeneous $\mathrm{MoS}_{2} @ \mathrm{MIL}-88(\mathrm{Fe})$ hybrid composite under UV irradiation.

Antibacterial activity of FeNPs was measured by the zone of inhibition for different pathogenic bacteria. The zone of inhibition of the selected bacterial isolates against
FeNPs and leaf extract was compared with the standard antibiotic chloramphenicol. The FeNPs showed maximum zone of inhibition against Gram negative bacteria $P$. vulgaris $(25 \mathrm{~mm}), V$. cholera $(25 \mathrm{~mm}), S$. flexneri $(23 \mathrm{~mm}), S$. typhi $(20 \mathrm{~mm}), K$. pneumoniae $(15 \mathrm{~mm})$ and $P$. aeruginosa (32 $\mathrm{mm})$ whereas, Gram positive $S$. aureus $(15 \mathrm{~mm})$ and S. epidermis $(17 \mathrm{~mm})$ exhibited minimum zone of inhibition for iron nanoparticles (Table 1). The zone of inhibition clearly indicated that the FeNPs had significant antibacterial activity against wide range of both Gram-positive and Gram-negative bacteria. It has been reported that the effect of FeNPs was mainly electrostatic attraction between 
Table 1 Antibacterial activity of the biosynthesized FeNPs and leaf extract

\begin{tabular}{llll}
\hline Bacterial isolates & \multicolumn{3}{l}{ Zone of inhibition (mm) } \\
\cline { 2 - 4 } & $\begin{array}{l}P . \\
\text { reticulatus } \\
\text { extract }\end{array}$ & & \\
& & & \\
\hline Gram negative bacteria & & Chloramphenicol \\
Proteus vulgaris & $10 \pm 1.3$ & $25 \pm 2.4$ & $30 \pm 2.5$ \\
Vibrio chlorae & $18 \pm 2.1$ & $25 \pm 3.2$ & $32 \pm 2.7$ \\
Shigellaflexneri & $12 \pm 1.0$ & $23 \pm 2.6$ & $36 \pm 2.5$ \\
Salmonella typhi & $12 \pm 1.0$ & $20 \pm 1.5$ & $32 \pm 3.1$ \\
Klebsiella pneumonia & $13 \pm 1.5$ & $15 \pm 1.2$ & $35 \pm 3.8$ \\
Pseudomonas aeruginosa & $50 \pm 4.8$ & $32 \pm 3.4$ & $42 \pm 4.2$ \\
Gram positive bacteria & & & \\
Staphylococcus aureus & $10 \pm 1.1$ & $15 \pm 1.3$ & $35 \pm 3.4$ \\
Streptococcus epidermis & $12 \pm 1.7$ & $17 \pm 1.1$ & $31 \pm 3.0$ \\
\hline
\end{tabular}

positively charged FeNPs and negatively charged bacterial cell wall and this phenomena leads to the formation of reactive oxygen species (ROS) caused by cell death ( $\mathrm{Li}$ et al. 2008; Burello and Worth 2011). The antibacterial activity was caused based on the fact that Fe ions released form iron oxide nanoparticles infused the bacterial cell membrane by attaching to the negatively charged cell wall (Ren et al. 2009; Sankar et al. 2013). Fe ions may indulge in cross linkage of nucleic acid strands by binding them with DNA of bacteria. This may lead to the disordered helical structure of DNA molecule which may be due to the denaturation of proteins and irregular of some biochemical processes in the cell, it may result the complete destruction of the bacterial cell (Yallappa et al. 2013). Ravishankar Rai and Jamuna Bai (2011) and Tong et al. (2012) reported that iron oxide nanoparticles can interact with thiol (-SH) group of the protein present on the bacterial cell wall that leads to the denaturation of surface protein along with the loss of cell membrane permeability, subsequently cause cell death. Also they act with phosphorus present inside the DNA by inactivating and inhibiting the enzyme activity leading to the death of bacteria.

The antifungal activity of the green synthesized FeNPs was compared with the standard antibiotic fluconozole. The fungicidal activity of FeNPs was found to be maximum in Rhizopus sp. and Trichoderma viridae with corresponding zone of inhibition of 31 and $30 \mathrm{~mm}$, respectively. A. fumigatus and A.niger showed a zone of inhibition of $25 \mathrm{~mm}$ and followed by A. flavus (18 mm), respectively (Table 2). The zone of inhibitions on the fungal plates clearly indicated the antifungal activity of FeNPs. It has been reported that the maximum zone of inhibition depends on the concentration of FeNPs and also spore concentration produced by the corresponding fungi. Abdeen and Salahuddin (2013) have
Table 2 Antifungal activity of the biosynthesized FeNPs and leaf extract

\begin{tabular}{llll}
\hline Fungal isolates & \multicolumn{3}{l}{ Zone of inhibition $(\mathrm{mm})$} \\
\cline { 2 - 4 } & $\begin{array}{l}\text { P. reticulatus } \\
\text { extract }\end{array}$ & FeNPs & Fluconazole \\
\hline Trichoderma viridae & $15 \pm 1.2$ & $30 \pm 2.2$ & $40 \pm 3.4$ \\
Aspergillus niger & $22 \pm 2.1$ & $25 \pm 2.3$ & $30 \pm 2.9$ \\
Aspergillus fumigatus & $20 \pm 2.0$ & $25 \pm 2.3$ & $30 \pm 2.8$ \\
Aspergillus flavus & $13 \pm 1.1$ & $18 \pm 1.9$ & $20 \pm 1.7$ \\
\hline
\end{tabular}

been reported that the iron nanoparticles possess promising antimicrobial activity against several human pathogens. Nehra et al. (2018) reported that the iron oxide NPs showed strong lethal effects towards the $A$. niger and $F$. solani. The broad spectrum of antibacterial and antifungal activity of the synthesized FeNPs could be used as potential antimicrobial agent in the field of clinical medicine. Similarly, zinc oxide nanoparticles were synthesized using funnel-shaped ivory flowers of Candelabra cactus which exhibited anticancer and antibacterial activity (Govarthanan et al. 2020).

The results of phytotoxicity assay such germination percentage, shoot length, root length and vigour index of green gram seeds grown with distilled water $\left(\mathrm{T}_{1}\right)$, Phyllanthus reticulatus leaf extract $\left(\mathrm{T}_{2}\right)$, and biosynthesized iron nanoparticles $\left(\mathrm{T}_{3}\right)$ were depicted in Table 3 . The germination percentage was maximum $\mathrm{T}_{1}(97 \%)$ followed $\mathrm{T}_{3}(93 \%)$ and $\mathrm{T}_{2}$ (90\%) (Fig. 6). Similar trend was noticed in the vigour index of green gram seeds (Table 3). The values observed for the shoot lengths of green gram were 3.83, 1.54 and $3.54 \mathrm{~cm}$ in $\mathrm{T}_{1}, \mathrm{~T}_{2}$ and $\mathrm{T}_{3}$, respectively. The root length was heightened in $\mathrm{T}_{1}(2.92 \mathrm{~cm})$ followed by $\mathrm{T}_{3}(1.35 \mathrm{~cm})$ and $\mathrm{T}_{2}$ $(0.69 \mathrm{~cm})$. Increase in the germination and seedling growth by biosynthesized iron oxide nanoparticles shows that iron with plant extract might have acted as stabilizer and proves to be non-toxic in nature. It has also been anticipated for the bioremediation of pollutants (Yavuz et al. 2006; Barrena et al. 2009). Literature also says that iron oxide nanoparticles act as non-toxic material in many fields (Ju-Nam and Lead 2008) and also perform as biostimulant and micronutrient (Liu et al. 2014).

\section{Conclusion}

Phyto-synthesis of FeNPs using P. reticulatus leaf extract is a cost effective, simple and eco-friendly method that excludes the hazards arising out of the use of harmful reducing and/or capping agents. The phyto-synthesized FeNPs have potential broad-spectrum of antibacterial and antifungal activity. Furthermore, the catalytic activity of FeNPs to degrade methylene blue, classic contaminant of water bodies 
Table 3 Phytotoxicity assay of green gram seeds grown with different treatments

\begin{tabular}{lllll}
\hline Treatments & $\begin{array}{l}\text { Germination per- } \\
\text { centage }\end{array}$ & Shoot length $(\mathrm{cm})$ & Root length $(\mathrm{cm})$ & Vigour index \\
\hline $\mathrm{T}_{1}$ & 97 & $3.83 \pm 0.24$ & $2.92 \pm 0.03$ & 655 \\
$\mathrm{~T}_{2}$ & 90 & $1.25 \pm 0.81$ & $0.69 \pm 0.60$ & 175 \\
$\mathrm{~T}_{3}$ & 93 & $3.54 \pm 0$ & $1.35 \pm 0.18$ & 455 \\
\hline
\end{tabular}

Values of Mean \pm Standard Deviation

Where, $\mathrm{T}_{1}$-Distilled water (Control), $\mathrm{T}_{2}$ - Leaf extract of $P$. reticulates, $\mathrm{T}_{3}$-Phytosynthesised iron nanoparticles
Fig. 6 Germination of green gram seeds using different treatments. $\mathrm{T}_{1}$-Distilled water (Control), $\mathrm{T}_{2}$ - Leaf extract of P.reticulatus, $\mathrm{T}_{3}$-Biosynthesised iron nanoparticles

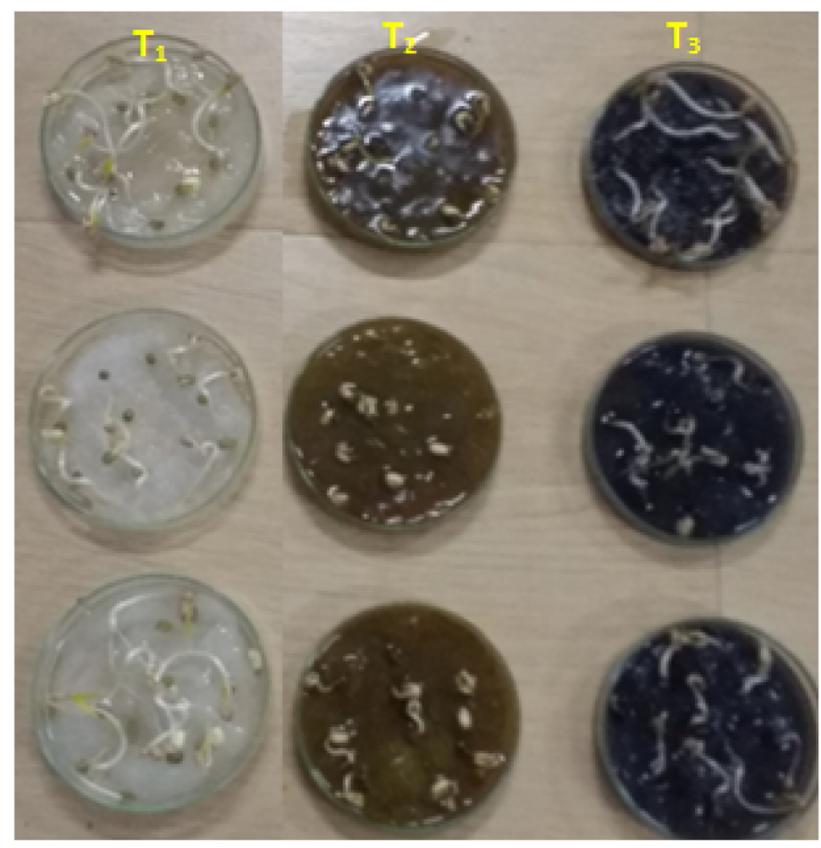

$\mathrm{T}_{1}$ - Distilled water (Control), $\mathrm{T}_{2}$ - Leaf extract of P.reticulatus, $\mathrm{T}_{3}$ - Biosynthesised iron nanoparticles was successfully investigated. The outcome of this study may find applications in therapeutics, agriculture and textile industries.

Acknowledgements The authors acknowledge the higher authorities of Avinashilingam Institute for Home Science and Higher Education for Women, Coimbatore for providing the facilities to conduct this study. This work was partly supported by the Korea Institute of Energy Technology Evaluation and Planning (KETEP) grant funded by the Korea government (MOTIE)

(No. 20194110100100, full-scale feasibility study of the stability and efficiency improvement of a biogas production facility based on biomass from urban/living environments). The authors extend their appreciation to the Researchers Supporting Project number (RSP2021/56), King Saud University, Riyadh, Saudi Arabia.

\section{Declarations}

Conflict of interest The authors declare that they have no conflict of interest.

\section{References}

Abdeen R, Salahuddin N (2013) Modified chitosan-clay nanocomposite as a drug delivery system intercalation and in vitro release of ibuprofen. J Chem. https://doi.org/10.1155/2013/ 576370

Ali A, Zafar H, Zia M et al (2016) Synthesis, characterization, applications, and challenges of iron oxide nanoparticles. Nanotechnol Sci Appl 9:49-67. https://doi.org/10.2147/NSA.S99986

Anupama N, Murali M, Jogaiah S, Amruthesh KN (2014) Crude oligossacarides from Alternaria solani with Bacillus subtilis enhance defense activity and induce resistance against early blight disease of tomato. Asian J Sci Technol 5:412-416

Arularasu MV, Anbarasu M, Poovaragan S et al (2018) Structural, optical, morphological and microbial studies on $\mathrm{SnO}_{2}$ nanoparticles prepared by co-precipitation method. J Nanosci Nanotechnol 18:3511-3517. https://doi.org/10.1166/jnn.2018.14658

Barrena R, Casals E, Colón J et al (2009) Evaluation of the ecotoxicity of model nanoparticles. Chemosphere 75:850-857. https:// doi.org/10.1016/j.chemosphere.2009.01.078 
Bauer AW, Kirby WMM, Sherris JC et al (1966) Antibiotic susceptibility testing by a standardized singledisk method. Am J Clin Pathol 36:493-496

Bishnoi S, Kumar A, Selvaraj R (2018) Facile synthesis of magnetic iron oxide nanoparticles using inedible Cynometra ramiflora fruit extract waste and their photocatalytic degradation of methylene blue dye. Mater Res Bull 97:121-127

Burello E, Worth AP (2011) A theoretical framework for predicting the oxidative stress potential of oxide nanoparticles. Nanotoxicology 5:228-235. https://doi.org/10.3109/17435390.2010.502980

Charbgoo F, Bin AM, Darroudi M (2017) Cerium oxide nanoparticles: green synthesis and biological applications. Int J Nanomedicine 12:1401-1413

Chen C, Liu J, Liu P, Yu B (2011) Investigation of photocatalytic degradation of methyl orange by using nano-sized $\mathrm{ZnO}$ catalysts. Adv Chem Eng Sci 01:9-14. https://doi.org/10.4236/aces.2011.11002

Devatha CP, Kumar A, Katte SY (2016) Green synthesis of iron nanoparticles using different leaf extracts for treatment of domestic waste water. J Clean Prod 139:1425-1435. https://doi.org/10. 1016/j.jclepro.2016.09.019

Ebrahiminezhad A, Taghizadeh S, Berenjian A et al (2017) Green synthesis of silver nanoparticles capped with natural carbohydrates using Ephedra intermedia. Nanosci \& Nanotechnology-Asia. https://doi.org/10.2174/2210681206666161006165643

Garole VJ, Choudhary BC, Tetgure SR et al (2018) Detoxification of toxic dyes using biosynthesized iron nanoparticles by photo-Fenton processes. Int J Environ Sci Technol 15:1649-1656. https:// doi.org/10.1007/s13762-017-1510-0

Goswami M, Baruah D, Das AM (2018) Green synthesis of silver nanoparticles supported on cellulose and their catalytic application in the scavenging of organic dyes. New J Chem 42(13):10868-10878

Gottimukkala KSV, Harika RP, Zamare D (2017) Green synthesis of iron nanoparticles using green tea leaves extract. J Nanomedine Biotherapeutic Discov 7(151):2

Govarthanan M, Srinivasan P, Selvankumar T et al (2020) Utilization of funnel-shaped ivory flowers of Candelabra cactus for zinc oxide nanoparticles synthesis and their in-vitro anti-cancer and antibacterial activity. Mater Lett 273:127951

Govarthanan M, Mythili R, Kim W et al (2021) Facile fabrication of (2D/2D) MoS2@MIL-88(Fe) interface-driven catalyst for efficient degradation of organic pollutants under visible light irradiation. J Hazard Mater 414:125522. https://doi.org/10.1016/j.jhazmat. 2021.125522

Huang L, Weng X, Chen Z et al (2014) Green synthesis of iron nanoparticles by various tea extracts: Comparative study of the reactivity. Spectrochim Acta - Part A Mol Biomol Spectrosc 130:295301. https://doi.org/10.1016/j.saa.2014.04.037

Ju-Nam Y, Lead JR (2008) Manufactured nanoparticles: An overview of their chemistry, interactions and potential environmental implications. Sci Total Environ 400:396-414. https://doi.org/10.1016/j. scitotenv.2008.06.042

Khatun H, Nesa L, Islam R et al (2014) Antidiabetic and antidiarrheal effects of the methanolic extract of Phyllanthus reticulatus leaves in mice. Asian Pacific J Reprod 3:121-127. https://doi.org/10. 1016/S2305-0500(14)60015-4

Kumar A, Gupta M (2005) Cytotoxicity suppression and cellular uptake enhancement of surface modified magnetic nanoparticles. Biomaterials 26:1565-1573. https://doi.org/10.1016/j.biomateria 1s.2004.05.022

Li N, Xia T, Nel AE (2008) The role of oxidative stress in ambient particulate matter-induced lung diseases and its implications in the toxicity of engineered nanoparticles. Free Radic Biol Med 44:1689-1699. https://doi.org/10.1016/j.freeradbiomed.2008.01. 028

Lin Z, Wu J, Xue R, Yang Y (2005) Spectroscopic characterization of Au3+ biosorption by waste biomass of Saccharomyces cerevisiae. Spectrochim Acta - Part A Mol Biomol Spectrosc 61:761-765. https://doi.org/10.1016/j.saa.2004.03.029

Litvin VA, Galagan RL, Minaev BF (2012) Kinetic and mechanism formation of silver nanoparticles coated by synthetic humic substances. Colloids Surfaces A Physicochem Eng Asp 414:234243. https://doi.org/10.1016/j.colsurfa.2012.08.036

Liu X, Huang N, Li H et al (2014) Multidentate polyethylene glycol modified gold nanorods for in vivo near-infrared photothermal cancer therapy. ACS Appl Mater Interfaces 6:5657-5668. https://doi.org/10.1021/am5001823

Mahmoud AA, El-Feky GS, Kamel R, Awad GEA (2011) Chitosan/ sulfobutylether- $\beta$-cyclodextrin nanoparticles as a potential approach for ocular drug delivery. Int J Pharm 413:229-236. https://doi.org/10.1016/j.ijpharm.2011.04.031

Maji SK, Pal A, Pal T, Adak A (2007) Modeling and fixed bed column adsorption of As(III) on laterite soil. Sep Purif Technol 56:284-290. https://doi.org/10.1016/j.seppur.2007.02.011

Mohan Kumar K, Mandal BK, Siva Kumar K et al (2013) Biobased green method to synthesise palladium and iron nanoparticles using Terminalia chebula aqueous extract. Spectrochim Acta Part A Mol Biomol Spectrosc 102:128-133. https://doi.org/10. 1016/j.saa.2012.10.015

Mythili R, Selvankumar T, Sudhakar C et al (2018) Utilization of market vegetable waste for silver nanoparticle synthesis and its antibacterial activity. Mater Lett 225:101-104. https://doi.org/ 10.1016/j.matlet.2018.04.111

Nehra P, Chauhan RP, Garg N, Verma K (2018) Antibacterial and antifungal activity of chitosan coated iron oxide nanoparticles. Br J Biomed Sci 4845:1-6. https://doi.org/10.1080/09674845. 2017.1347362

Prabhakar R, Samadder SR, Jyotsana (2017) Aquatic and terrestrial weed mediated synthesis of iron nanoparticles for possible application in wastewater remediation. J Clean Prod 168:12011210. https://doi.org/10.1016/j.jclepro.2017.09.063

Praveen A, Lakshmi Narayana Rao G, Balakrishna B (2018) Performance and emission characteristics of a diesel engine using Calophyllum Inophyllum biodiesel blends with TiO2nanoadditives and EGR. Egypt J Pet. https://doi.org/10.1016/j.ejpe. 2017.10.008

Raj S, Chand Mali S, Trivedi R (2018) Green synthesis and characterization of silver nanoparticles using Enicostemma axillare (Lam.) leaf extract. Biochem Biophys Res Commun 503:2814-2819. https://doi.org/10.1016/j.bbrc.2018.08.045

Ravishankar Rai V, Jamuna Bai A (2011) Nanoparticles and their potential application as antimicrobials, science against microbial pathogens: communicating current. research and technological advances. In: Méndez-Vilas A (ed) Formatex, Microbiology series, vol 1, no 3, pp 197-209

Ren G, Hu D, Cheng EWC et al (2009) Characterisation of copper oxide nanoparticles for antimicrobial applications. Int J Antimicrob Agents 33:587-590. https://doi.org/10.1016/j.ijantimicag. 2008.12.004

Sankar R, Karthik A, Prabu A et al (2013) Origanum vulgare mediated biosynthesis of silver nanoparticles for its antibacterial and anticancer activity. Colloids Surfaces B Biointerfaces 108:80-84. https://doi.org/10.1016/j.colsurfb.2013.02.033

Selvam K, Sudhakar C, Govarthanan M et al (2017) Eco-friendly biosynthesis and characterization of silver nanoparticles using Tinospora cordifolia (Thunb.) Miers and evaluate its antibacterial, antioxidant potential. J Radiat Res Appl Sci 10:6-12. https:// doi.org/10.1016/j.jrras.2016.02.005

Sengottaiyan A, Aravinthan A, Sudhakar C et al (2016) Synthesis and characterization of Solanum nigrum-mediated silver nanoparticles and its protective effect on alloxan-induced diabetic rats. J Nanostructure Chem 6:41-48. https://doi.org/10.1007/ s40097-015-0178-6 
Shah M, Fawcett D, Sharma S et al (2015) Green synthesis of metallic nanoparticles via biological entities. Materials 8(11):7279-7308

Shahwan T, Abu Sirriah S, Nairat M et al (2011) Green synthesis of iron nanoparticles and their application as a Fenton-like catalyst for the degradation of aqueous cationic and anionic dyes. Chem Eng J 172:258-266. https://doi.org/10.1016/j.cej.2011.05.103

Suruthika B, Poonkothai M, Lalitha P et al (2020) Synthesis of nanosilver from Navicula cincta and the evaluation of its antimicrobial activity. Micro Nano Lett 15(2):119-124. https://doi.org/10.1049/ mnl.2019.0365

Tong H, Ouyang S, Bi Y et al (2012) Nano-photocatalytic materials: possibilities and challenges. Adv Mater 24:229-251. https://doi. org/10.1002/adma.201102752

Tsibul'nikova AV, Bryukhanov VV, Slezhkin VA (2015) Enhancement of singlet-triplet energy transfer between dyes in a polymer film by surface plasmons of gold nanoparticles. Russ Phys J 57:17161724. https://doi.org/10.1007/s11182-015-0443-7

USEPA (1996) Soil screening guidance: technical background document. Office of Emergency and Remedial Response, Washington, DC. https://doi.org/10.1016/j.materresbull.2017.08.040. EPA/540/ R95/128

Vishal P, Agrawal YK (2011) Current status and advanced approaches in ocular drug delivery system. Global Trends Pharma Sci 2(2):131-148
Wang T, Jin X, Chen Z et al (2014) Science of the Total Environment Green synthesis of Fe nanoparticles using eucalyptus leaf extracts for treatment of eutrophic wastewater. Sci Total Environ 466-467:210-213. https://doi.org/10.1016/j.scitotenv.2013.07.022

Weng X, Huang L, Chen Z et al (2013) Synthesis of iron-based nanoparticles by green tea extract and their degradation of malachite. Ind Crops Prod 51:342-347. https://doi.org/10.1016/j.indcrop. 2013.09.024

Yallappa S, Manjanna J, Sindhe MA et al (2013) Microwave assisted rapid synthesis and biological evaluation of stable copper nanoparticles using T. arjuna bark extract. Spectrochim Acta - Part A Mol Biomol Spectrosc 110:108-115. https://doi.org/10.1016/j. saa.2013.03.005

Yavuz H, Denizli A, Güngüneş H et al (2006) Biosorption of mercury on magnetically modified yeast cells. Sep Purif Technol 52:253260. https://doi.org/10.1016/j.seppur.2006.05.001

Publisher's Note Springer Nature remains neutral with regard to jurisdictional claims in published maps and institutional affiliations. 